\title{
Identifying major paleoenvironmental changes in the southern Red Sea continental shelf with the use of high- resolution XRF-core scanning data
}

\author{
FRANCESCA PARASCHOS ${ }^{1}$, ELENI KABERI ${ }^{2}$, \\ STYLIANOS ILIAKIS ${ }^{1}$, SPYROS SERGIOU ${ }^{3}$, MARIA \\ GERAGA $^{3}$, SÖNKE SZIDAT ${ }^{4}$ AND DIMITRIS \\ SAKELLARIOU $^{1}$ \\ ${ }^{1}$ Hellenic Center for Marine Research \\ ${ }^{2}$ Hellenic Centre for Marine Research \\ ${ }^{3}$ University of Patras \\ ${ }^{4}$ University of Bern \\ Presenting Author: fparaskos@hcmr.gr
}

X-ray fluorescence core scanning (XRF-CS) has been proved to be an invaluable tool in paleoenvironmental and paleoclimatic research as it can provide continuous and high-resolution chemical records of marine sediment cores. The value of the produced data sets is that they can be readily used for preliminary stratigraphic interpretations and the identification of major climatically driven changes in sediment composition based on well established elemental ratios. However, calibration of the XRF-CS produced data is necessary in order to utilize these elemental intensities as accurately as possible and perform multivariate statistical analyses. In this study, we present findings from the calibration and interpretation of the XRF-core scanning data of two marine sediment cores retrieved from the continental shelf of the southern Red Sea which together cover the last 30ka.

Both cores were lithologically described, dated and scanned with an Avaatech XRF core scanner. The XRF elemental counts were calibrated with representative discrete sub-samples and converted into concentrations in order to reduce the uncertainties associated with the scanning procedure. In order to accomplish this conversion a multivariate log-ratio calibration (MLC) [1] approach was used which basically calibrates all elements simultaneously through a centered log-ratio (clr) transformation.

Cross-plotting of the reference concentrations and the MLC results indicates a strong correlation for most elements $\left(\mathrm{r}^{2}\right.$ values between $0.7-0.95$ ) and therefore suggests a robust calibration. Interpretation of the MLC produced elemental log-ratios gives us clear indications of the climatic shifts that affected the southern Red Sea during the late MIS3, MIS2 and MIS1. Log-ratios of the outer shelf core FA09 (0-30ka), clearly detect the paleoenvironmental conditions and events associated with the last glacial lowstand, the deglacial period/subsequent sea-level rise and the Holocene climatic optimum. On the other hand, logratios of the inner shelf core FA14 (0-10ka), appear to be less variant but nonetheless track the changes between the humid early-mid Holocene, succeeding deglaciation, and the arid conditions that prevailed during the mid-late Holocene.

[1] Weltje, G.J., et al., 2015. Prediction of geochemical composition from XRF core scanner data: a new multivariate approach including automatic selection of calibration samples 